\title{
Philosophiques
}

\section{Livres reçus (printemps 2000)}

Volume 27, numéro 1, printemps 2000

Le matérialisme contemporain

URI : https://id.erudit.org/iderudit/004953ar

DOI : https://doi.org/10.7202/004953ar

Aller au sommaire du numéro

Éditeur(s)

Société de philosophie du Québec

ISSN

0316-2923 (imprimé)

1492-1391 (numérique)

Découvrir la revue

Citer ce document

(2000). Livres reçus (printemps 2000). Philosophiques, 27(1), 227-228.

https://doi.org/10.7202/004953ar d'utilisation que vous pouvez consulter en ligne.

https://apropos.erudit.org/fr/usagers/politique-dutilisation/ 


\section{Livres reçus (printemps 2000)}

Antonioli, M anola, 1999. D eleuze et l'histoire de la philosophie. Paris, Kimé, $122 \mathrm{p}$.

Atlan, Henri, 1999. Les étincelles du hasard. Connaissance spermatique, tome 1, Paris, Seuil (coll. «La librairie du xx siècle »), 392 p.

Bouton, Christophe, 2000. Temps et Esprit dans la philosophie de H egel. De Francfort à léna, Paris, Vrin, (coll. «Temps modernes »), 319 p.

Carrilho, M anuel M aria, 1999. Rhétoriques de la modernité. Paris, PUF, (coll. «Q uadrige»), $175 \mathrm{p}$.

Cléro, Jean-Pierre, 2000. Théorie de la perception. De l'espace à l'émotion.

Paris, PUF, (coll. «L'interrogation philosophique»), 319 p.

Delacampagne, Christian, 2000. $\mathrm{H}$ istoire de la philosophie au $\mathrm{xx}$ e siècle. Paris, Seuil, (coll. « Points essais »), 404 p.

Demonet, M arie-Luce (dir.), 1999. M ontaigne et la question de I'homme.

Paris, PUF, (coll. «D ébats philosophiques»).

Dortier, Jean-François (dir.), 1999. Philosophies de notre temps. Auxerres,

Sciences humaines, $359 \mathrm{p}$.

Dumouchel, Daniel, 1999. Kant et la genèse de la subjectivité esthétique.

Paris, Vrin, (coll. « Histoire de la philosophie »), 305 p.

Edelman, Bernard, 1999. N ietzsche. Un continent perdu. Paris, PUF, (coll. «Perspectives critiques »), $366 \mathrm{p}$.

Gagnon, M aurice et $H$ ébert, Daniel, 2000. En quête de science. Introducton à l'épistémologie. Saint-L aurent, Fides, 309 p.

Gouin, Jean-Luc, 1999. Hegel ou la Raison intégrale suivi de Aimer penser mourir : $\mathrm{H}$ egel, N ietzsche, Freud en miroir, M ontréal. Bellarmin, $225 \mathrm{p}$.

Grillo, Éric, 2000. Intentionnalité et signifiance: une approche dialogique. Bern, Peter Lang, $392 \mathrm{p}$.

Grondin, Jean, 1999. Introduction à Hans-Georg Gadamer. Paris, Cerf (coll. « La nuit surveillée »), $232 \mathrm{p}$.

Guilhaumou, Jacques, 1998. La parole des sans. Les mouvements actuels à l'épreuve de la Révolution française. Fontenay, éditions ENS, (coll. « Feuillets »), $140 \mathrm{p}$.

Jaulin, Annick, 1999. Aristote. La métaphysique. Paris, PUF, (coll. «Philosophies »), $127 \mathrm{p}$.

Koula M ellos et Patrick Savidan (dir.), 1999. Pluralisme et délibération. E njeux en philosophie politique contemporaine. O ttawa, Presses de l'Université d'Ottawa, $193 \mathrm{p}$.

Kistler, Max, 1999. Causalité et loi de la nature. Paris, Vrin, (coll. « M athesis »), Paris, $311 \mathrm{p}$.

Lazzeri, Christian, 1999. Spinoza. Puissance et impuissance de la raison. Paris, PUF, (coll. « Débats philosophiques »), 115 p. 
Lonergan, Bernard, 2000. La compréhension de l'être. Saint-Laurent, Bellarmin, $422 \mathrm{p}$.

$\mathrm{M}$ achiavel, $\mathrm{N}$ icolas, 2000. Le Prince. traduction et commentaire de JeanLouis Fournel et Jean-Claude Zancarini, Paris, PUF, (coll. «Fondements de la philosophie politique »), $640 \mathrm{p}$.

M azzara, Giuseppe, 1999. Gorgia/L a Retorica del Verosimile. Siegburg, Academia Verlag.

Nadeau, Robert, 1999. Vocabulaire technique et analytique de l'épistémologie. Paris, PUF, (coll. «Premier cycle »), 872 p.

Panaccio, Claude, 1999. Le discours intérieur de Platon à Guillaume d'O ccam. Paris, Seuil, (coll. « Des travaux »), 341 p.

Renaud, François, 1999. D ie R esokratisierung Platons. Siegburg, A cademia Verlag.

Talbot, Gilbert, 1999. Phil et Sophie ou de l'être humain. Q uébec, Le loup de Gouttière, $84 \mathrm{p}$.

Venet, Gisèle (dir.), 1998. L e mal et ses masques. Théâtre, imaginaire, société. Fontenay, éditions EN S, (coll. «Signes »), 458 p.

Zancarini, Jean-Claude, 2000. Le Droit de résistance, $X I I^{e}-X X^{e}$ siècles. Fontenay, éditions EN S, (coll. «Theoria »).

Les personnes désireuses de faire un compte-rendu de l'un ou l'autre des ouvrages qui apparaissent dans cette liste sont priées de s'adresser à :

\author{
Daniel Dumouchel \\ Université de M ontréal \\ Département de philosophie \\ C.P. 6128 succ. Centre-ville \\ $M$ ontréal (Q uébec), $\mathrm{H} 3 \mathrm{C}$ 3J 7 \\ Tél.: (514) 343-6484 \\ Télec.: (514) 343-7899
}

Courriel : dumouchd@netcourrier.com 